\title{
A IMAGÉTICA DO INDÍGENA DO SÉCULO XIX POR SPIX E MARTIUS'
}

\section{INDIAN IMAGERY OF THE NINETEENTH CENTURY BY SPIX AND MARTIUS}

\author{
Helder Fabricio Brito Ribeiro² \\ http://lattes.cnpq.br/8169625307810329
}

Vânia Torres Costa ${ }^{3}$

http://lattes.cnpq.br/7517564393392394

Recebido em 4 de fevereiro de 2019

Aceito em 14 de dezembro de 2019

RESUMO: O presente artigo faz uma reflexão sobre a imagem do indígena produzida a partir das narrativas dos viajantes que percorreram a Amazônia no século XIX, especialmente as ilustrações resultantes da interação com os viajantes Johann Baptist von Spix e Carl Friedrich Philipp von Martius. O estudo analisa a imagem como discurso produtor de sentidos a partir de autores estrangeiros, com o intuito de problematizar modos de dizer sobre os sujeitos locais, sua cultura, seus hábitos e seus costumes. As leituras das imagens têm como base as teorias de Martine Joly (2013) que nos permitem observar as imagens como signos que classificam os sujeitos como exemplares raros, estranhos, descontextualizados de suas culturas.

Palavras-chave: Indígena. Imagética. Viajantes. Cultura. Amazônia.

\begin{abstract}
This article reflects on the image of the Indian produced from the narratives of travelers who visited the Amazon in the nineteenth century, especially the illustrations resulting from the interaction with travelers and Johann Baptist von Spix Carl Friedrich Philipp von Martius. The study analyzes the image as a producer of senses speech from foreign authors, in order to discuss ways of speaking about local subjects, their culture, their habits and customs. The readings of the images are based on the theories of Martine Joly (2013) that allow us to observe the images as signs that classify subjects as rare, strange specimens, decontextualized from their cultures.
\end{abstract}

Keywords: Indian. Imagery. Travelers. Culture. Amazon.

\footnotetext{
${ }^{1}$ Este trabalho é resultante da pesquisa 'Entre Viajantes e jornalistas: um olhar sobre os saberes tecidos na escrita do 'outro' amazônico", realizado na Universidade da Amazônia (Unama), no Programa de Pós-Graduação em Comunicação, Linguagens e Cultura (PPGCLC), à epoca coordenado pela professora Vânia Torres Costa, que esteve neste Programa até o ano de 2017. Helder Ribeiro foi bolsista do projeto, com o apoio da Fundação Instituto para o Desenvolvimento da Amazônia (FIDESA). Este artigo foi apresentadono II Colóquio Internacional de Discurso e Mídia na Amazônia (DCIMA / NOV. 2015) e revisado para publicação nesta revista.

${ }^{2}$ Doutorando em Comunicação, Linguagens e Cultura da Universidade da Amazônia - UNAMA. Mestre em Comunicação, Linguagens e Cultura da Universidade da Amazônia - UNAMA. Graduado pela Universidade da Amazônia - UNAMA (2000). E-mail: helderribeiro_pa@yahoo.com.br.

${ }^{3}$ Doutora em Comunicação pela Universidade Federal Fluminense (UFF), Mestre em Planejamento do Desenvolvimento pelo Núcleo de Altos Estudos Amazônicos (NAEA) - Universidade Federal do Pará (UFPA). Graduada em Comunicação - Jornalismo (UFPA). Professora da Faculdade de Comunicação da Universidade Federal do Pará (UFPA) e do Programa de Pós-Graduação em Comunicação, Cultura e Amazônia (PPGCOM). E-mail: professoravaniatorres@gmail.com.
} 


\section{INTRODUÇÃO}

Várias expedições de valor científico foram realizadas no Brasil no século XIX. O interesse dos europeus pelo continente americano como nova fronteira a ser conquistada, desbravada, conhecida e explorada era grande. Entre esses viajantes destacamos os naturalistas alemães Johann Baptist von Spix e Carl Friedrich Philipp von Martius. O material produzido pelos viajantes oferece rico material para pesquisa sobre o modo como eram vistos os povos originários do Brasil, tais como vestimentas, alimentação, rituais, moradia etc.

A expedição percorreu o Rio de Janeiro, Minas Gerais, São Paulo, Piauí, Pernambuco, Bahia, Maranhão, Pará e Amazonas, sendo esses dois últimos estados o foco de interesse desta pesquisa. Na Amazônia, os naturalistas identificaram diversos grupos étnicos, ao longo da Margem do Rio Moju, nos Sertões do Amazonas e no Rio Tapajós: Tapajós, Maués, Mundurucus, Juris, Uainumás, Juruena, Arinos, Apiacás, Manaus, Purupurus, Japurá, Uaraicu, Maxurunas, Tecuna, Macuná, Cauixaná, Tupixaba e Miranhas.

Este artigo tem como objetivo analisar as imagens produzidas sobre os sujeitos amazônicos a partir da obra 'Viagem pelo Brasil: 1817-1820', de Spix e Martius, observando a forma como os indígenas foram produzidos nesse diário de campo dos viajantes. E a partir da leitura da obra, pretendemos problematizar os desenhos que ilustram a narrativa dos viajantes.

Utilizamos os recursos da análise da imagem, a partir dos conceitos de Martine Joly, para quem a imagem é uma representação social, "algo que se assemelha a outra coisa" (JOLY, 2013, p. 38). Nesse sentido, interessa-nos observar as ilustrações dos viajantes como imagens fabricadas para ilustrar modelos de pessoas, dos habitantes de áreas amazônicas.

Após a leitura da obra 'Viagem pelo Brasil', foram elaboradas tabelas de descrição imagética para todas as figuras presentes nos relatos. Como corpus desta análise, interessa-nos as ilustrações que trazem os sujeitos, portanto as demais, que se limitavam à floresta ou ao cenário amazônico, foram descartadas. Das 35 ilustrações contidas nos relatos de Martius e Spix na região Amazônica, 20 foram selecionadas por representarem figuras humanas. É sobre esse recorte que teceremos nossa análise.

\section{O QUE OS VIAJANTES TRAZEM NA BAGAGEM}

Navegar por terras estrangeiras é percorrer territórios desconhecidos, novos, repletos de atrativos, surpresas. Viajar demanda deslocamento em busca de algo. Mas o que vieram buscar aqui as 42 expedições de naturalistas que percorreram a região entre os séculos XVI e XX, mencionadas por Meireles Filho (2009)? As expedições buscavam riquezas, matériasprimas em uma 'selva' inexplorada do ponto de vista da economia capitalista, que já avançava no resto do mundo. Mas buscavam também conhecer, expandir o controle imperialista sobre novos territórios, adquirir conhecimentos sobre os produtos da floresta e exploração das populações locais. A Amazônia torna-se o epicentro de produção de novas teorias em um contexto em que a ciência despontava como a verdade do mundo, desde que comprovasse o que afirmava.

As expedições tornam-se então o momento do encontro desses cientistas com seus objetos de pesquisa: a floresta e o indígena. A América como terra in natura, habitada por homens iletrados, vivendo em condições completamente diferentes dos costumes europeus, é um referente histórico-cultural gerador de textos significativos dessa relação entre o viajante 
europeu e os indígenas do Brasil. Entre a Europa que se institui como civilizada, moderna, urbana, letrada, branca e a Amazônia, vista como rural, selvagem, atrasada, indígena.

São esses movimentos e encontros de sociedades diversas e do avançar paralelo da ciência, que vão gerar posteriormente o desenvolvimento do conceito de cultura, enquanto reflexão teórica. Para Laraia (2001), o primeiro conceito antropológico do significado de cultura surgiu em 1871, com Edward Tylor, que defendia ser um fenômeno natural, com causas e regularidades, e afirmava poder analisar a igualdade das naturezas humanas a partir da comparação das raças com o mesmo grau de civilização. A diversidade tornava-se uma consequência da desigualdade de estágios no processo de evolução, colocando de um lado o ‘europeu civilizado' e do outro o ‘indígena selvagem'.

Correntes teóricas como o evolucionismo social, o positivismo, o naturalismo e o socialdarwinismo ganham forças de difusão no Brasil durante este período. A intenção é mudar a imagem internacional do país, associando-o à modernização, e não mais à selva (SCHWARCZ, 1993). É no século XIX que o conceito de raça começa a ser debatido juntamente com o conceito de civilização. Logo após o desencadeamento das revoluções burguesas, a Europa segue propósitos 'igualitários', com a constituição dos estados nacionais e o surgimento do cidadão de direitos e deveres. A face obscura desse avanço capitalista em busca de matériasprimas, riqueza e escravos se dá com o grande fluxo das navegações de intuito colonizador.

Tais correntes e escolas teóricas chegam no Brasil na década de 1870 para explicar as diferenças internas. Schwarcz (1993) chama de 'imperialismo interno' a metodologia de classificação social, de corrente evolucionista e determinista, utilizada pela política imperialista na Europa, que define a hierarquia social a partir da variação racial. Segundo Schwarcz (1993), as narrativas resultantes de viagens para os novos continentes abalaram o imaginário europeu, trazendo relatos sobre criaturas extraordinárias, referindo-se a povos selvagens (SCHWARCZ, 1993).

Essas classificações e estranhamentos com relação às populações nativas do continente americano irão percorrer os relatos dos viajantes naturalistas, inaptos a ver a diferença como pluralidade e diversidade. Suas expedições tinham como propósito promover uma taxonomia do 'outro', não com o intuito de compreendê-los ou de escutá-los, mas na maioria das vezes eram descritos apenas porque faziam parte da paisagem (TODOROV, 1988).

\section{OS RELATOS DA 'VIAGEM PELO BRASIL': O DESVELAR DOS DIÁRIOS DE BORDO}

A partir das informações contidas no livro 'Viagem pelo Brasil: 1817-1820', observamos os modos como os naturalistas se referiam aos indígenas, descritos como 'livres', 'não civilizados', 'mansos' e com um linguajar diferenciado. Spix e Martius (1981) relatam que os indígenas viviam da forma mais simples possível, o que correspondia a hábitos e costumes baseados na terra que cultivavam e na obtenção de alimentos para o seu sustento. Eles afirmam que os indígenas nunca tiveram contato com a civilização. Ressaltam a simplicidade, a ingenuidade e o isolamento desse povo devido à falta de execução de leis, em que seus dirigentes (caciques) não tem noção da responsabilidade do Estado para com eles, como relatam no livro.

Pensara-se que os indígenas, quando pudessem viver com todas as prerrogativas de homens livres entre os outros cidadãos, preferem essa condição à sua vida livre de selvagens; mas nem o caráter nem as luzes dessa desgraçada raça favorecia ainda a independência civil, e, nessa 
impotência, não lhes restava outro alvitre, senão continuar como serventes dos brancos ou regressar às suas matas virgens (SPIX; MARTIUS, 1981. p.46 - Notas do capítulo I).

Esses relatos mencionam o indígena como um indivíduo livre, mas com sua liberdade questionada, com argumentos sobre sua ignorância em desconhecer seus direitos. Assim, é visível a crítica ao seu desinteresse por tornar-se um civilizado, e principalmente reconhecer os seus benefícios e suas leis.

Os indígenas serviam aos viajantes como remadores nos grandes rios da região. Durante essas navegações muitas situações de risco aconteciam. Os diários de viagens mencionam que em alguns casos os indígenas abandonavam as embarcações e deixavam os passageiros em apuros, como contam Martius e Spix no episódio em que o Governador de Grão-Pará, Francisco de Mendonça Furtado viajava entre Belém a a ilha do Marajó: “os indígenas, obrigados a remar, pularam todos juntos no rio e nadaram para terra, vendo-se o capitãogeneral e seus oficiais coagidos a empunhar e manejar os remos"4.

Os relatos dos viajantes também trazem a vivência do indígena na cidade com suas famílias, o que a cada dia tornava-se mais frequente àquela época. Presentes em trabalhos domésticos, mais do que os negros, são observados como vítimas de opressões sofridas, péssimas condições de trabalho e de morada, que quando comparadas ao passado, não despertam nos viajantes a impressão de que algo mudou desde que foram "domesticados" pelos brancos.

Um dos pontos relevantes, citado nos relatos, é o desenvolvimento do comércio no Pará, que provém de várias regiões do interior, como Cametá, Gurupá, Santarém e do Rio Negro. Os indígenas descarregavam os artigos trazidos e distribuíam aos comerciários. Nesses textos, os naturalistas demonstram a disposição do indígena ao trabalho, desprendido de seus atributos sociais e morais, apresentando-se seminus, como agem nas aldeias. Em outro trecho do livro, o indígena do Pará lhes parece muito pacato com relação aos indígenas maranhenses.

A razão desta pouca inciativa deve ser atribuída, por um lado, à escassez de grandes capitais e, por outro lado, ao gênio pacato do paraense, que se satisfaz com menor lucro e não acompanha o espírito ambicioso de especulação de seus vizinhos, os maranhenses (SPIX; MARTIUS, 1981, p.34).

Os relatos trazem com frequência a comparação do homem do Grão-Pará com com o europeu. Um outro exemplo refere-se à liberdade dos indígenas em manter sua casa aberta sem desconfiar do seu vizinho. A harmonia cotidiana das aldeias é retratada no modo como o indígena aparece repleto de um sentimento justo, diferente do modo como viam os negros. Os fatos vivenciados pelos indígenas impressionavam os viajantes, que os denominavam como 'aborígines' e os tratavam como algo ‘muito esquisito' e 'incompreensível'.

A maneira como se referiam aos fenômenos naturais, à pororoca, às cheias das grandes águas e ao rolar da preamar é vista como representação que toma a natureza como algo ligado aos maus espíritos, conforme consta nos relatos. Essas narrativas míticas dos indígenas, fundamentadas em crenças que atravessam gerações, agiriam na formação de seu caráter a partir das observações de Martius e Spix: são confiantes 'homens vermelhos', baseados em lendas como a mãe-do-rio, das Amazonas, homens sem cabeça, do conúbio de índias (SPIX; MARTIUS, 1981, p 94-95).

${ }^{4}$ SPIX; MARTIUS, 1981. p. 26. 
Laplantine e Trindade (2012) relatam que o simbólico comporta um componente racional real e representa o real ou tudo aquilo que é indispensável para o homem agir ou pensar. O simbólico se faz presente em toda a vida social, na situação familiar, econômica, religiosa, política, etc. Embora não esgotem todas as experiências sociais, os símbolos mobilizam de maneira afetiva as ações humanas e as legitimam. A vida social é impossível fora de uma rede simbólica.

Este simbólico encontra-se muito presente nos rituais indígenas, ressignificados por novas gerações. O real existe a partir das ideias, signos, símbolos atribuídos à realidade reconhecida ou percebida. As representações atreladas à imagem como símbolos significam substituições do objeto, com a necessidade de examinar a natureza, a relação social e a representação, como imagem ou símbolo (LAPLANTINE; TRINDADE, 2012).

Os viajantes descrevem as habilidades e as atividades dos indígenas, afirmando que apesar de toda a sua 'incultura', eles possuem grandes conhecimentos, gradativamente perdidos a partir do contato com o homem branco, o que os tornou aculturados. Os conhecimentos culturais dos indígenas foram se perdendo com a colonização, abrindo caminho para as dificuldades, como as doenças endêmicas (varíola e sarampo), doenças que causaram devastações nas tribos, a perda da individualidade dos grupos ali presentes e a unificação das línguas (SPIX; MARTIUS, 1981, p. 102-103).

Todas essas questões partem do princípio de que os indígenas foram colonizados com o propósito de fornecer o máximo de informações e riquezas para fortalecer politicamente a Europa, segundos relatos dos viajantes aqui ressaltados. Como relato final do livro, temos as expedições do Rio Madeira, em que os viajantes navegavam armados com o argumento de defesa contra os inimigos, os indígenas que habitavam a região. 'Tinham a finalidade de 'educar' essas tribos, mas relatam que poucos conseguiam mudar. A hostilidade do povo indígena sempre se fazia constante na luta e defesa de seus territórios diante das imposições dos colonizadores, pois os jesuítas eram os únicos que naquele momento tinham influências sobre os mesmos (SPIX; MARTIUS, 1981. p. 287-288. Notas do Cap. VI).

\section{A IMAGEM DOS INDÍGENAS NOS RELATOS DOS VIAJANTES}

É notória a importância das representações imagéticas nas sociedades, pois para Joly (2013) é a forma de sinalização de contextos culturais em nível de informação, comunicação e expressão. As imagens tornam-se presentes a partir do processo de observação, ora atrelado ao verbal, ou como código de importância para a compreensão na sociedade e suas tradições. As imagens retiradas dos relatos de Spix e Martius aparecem ao longo do diário de campo das expedições, como ilustração e comprovação do texto verbal, visto que àquela época ainda não se tinha a fotografia como recurso de documentação na pesquisa. Joly aponta que é necessário observar os limites dos pontos do referencial de análise, aonde se quer chegar, que argumentos apresentam, pois para analisar uma imagem necessitamos definir o objeto, o saber, a receptividade e principalmente estudar a história do local.

Os viajantes, como colecionadores, iam selecionando e registrando tudo o que lhes parecia diferente para ser catalogado e analisado. Dessa forma, observa-se que o estranhamento é posto em cena em jogos de relações, como diz Foucault (1995), o que nos permite identificar frequências e ausências da produção discursiva. Foucault aponta, na citação a seguir, que só compreendemos um texto quando observamos os contextos da enunciação, sua origem e 
circulação. As imagens que analisamos aqui são signos que colocam em cena a diferença e o estranhamento que o novo, representado pelos artefatos indígenas, provoca nos viajantes. São resultantes de tensionamentos da relação entre 'eu' e o 'outro': aquele que relata e conta sobre aquele que é o sujeito narrado.

Trata-se de compreender o enunciado na estreiteza e singularidade de sua situação; de determinar as condições de sua existência, de fixar seus limites de forma mais justa, de estabelecer suas correlações com outros enunciados a que pode estar ligado, de mostrar que outras formas de enunciação exclui (FOUCAULT, 1995, p.31).

Nesta imagem (figura 01) temos os utensílios e armas dos indígenas. Estão figurados em tamanho proporcional, pertencendo a diferentes etnias, coletadas, sobretudo, durante a viagem pelo Amazonas. Enumeradas, retratam os objetos e suas descendências: algumas das localidades na província do Rio Negro, habitantes da Ilha das Flores, perto da costa, ao sul da Baia de Todos os Santos de tribos distintas, como Jumás, Mainas, Maués, Tecunas, Miranhas, Camcãs e Passés. Esses artefatos e traçados são amostras de objetos de uso cotidiano, tais como na culinária, na caça, pesca e nos momentos de descanso, como a rede no centro da imagem (SPIX; MARTIUS, 1981. p. 123-124).

Figura 01: Quadro de utensílios

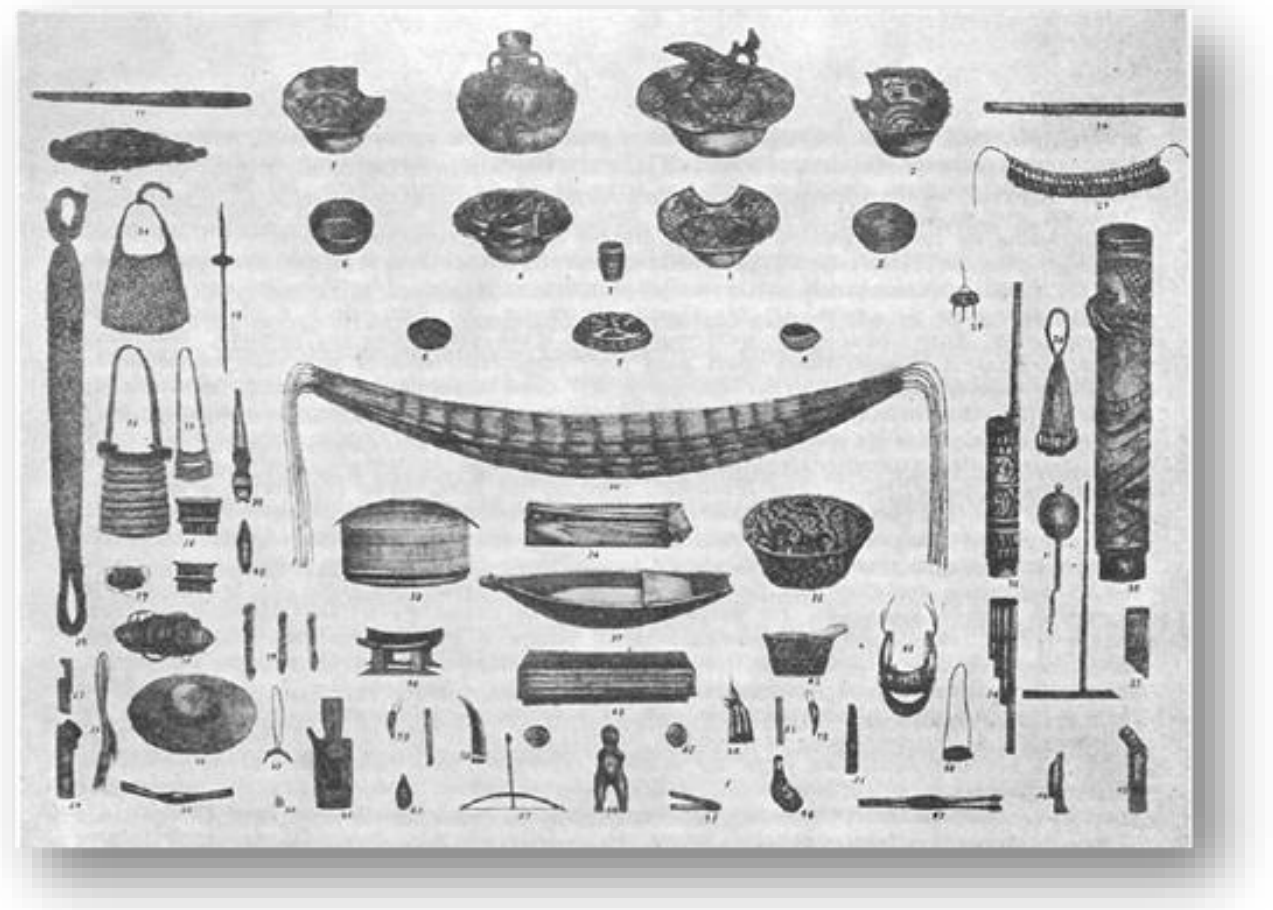

Fonte: o Livro A Viagem pelo Brasil - 1817-1820 de Spix e Martius, 1981. p.123.

A figura 02 também retrata o cotidiano da vida dos indígenas em situação específica que representa a tensão e os conflitos diante da presença do branco, nesta imagem retratado com uma arma de fogo nas mãos dirigindo-se aos nativos. A imagem mostra uma maloca, feita de folhas e troncos de árvores, com uma mulher indígena em rede de palha ao fundo. Um nativo com o corpo pintado com grafismos leva o homem branco até a maloca, e um rapaz 
acompanha o viajante, provavelmente um dos negros nativos que o guiou. Ao analisar a imagem dentro de uma visão estilística, observamos que está bem enquadrada no aspecto proporcional. O jogo de luz e sombra corresponde ao foco de luminosidade que provém de uma cena repressiva da presença do branco.

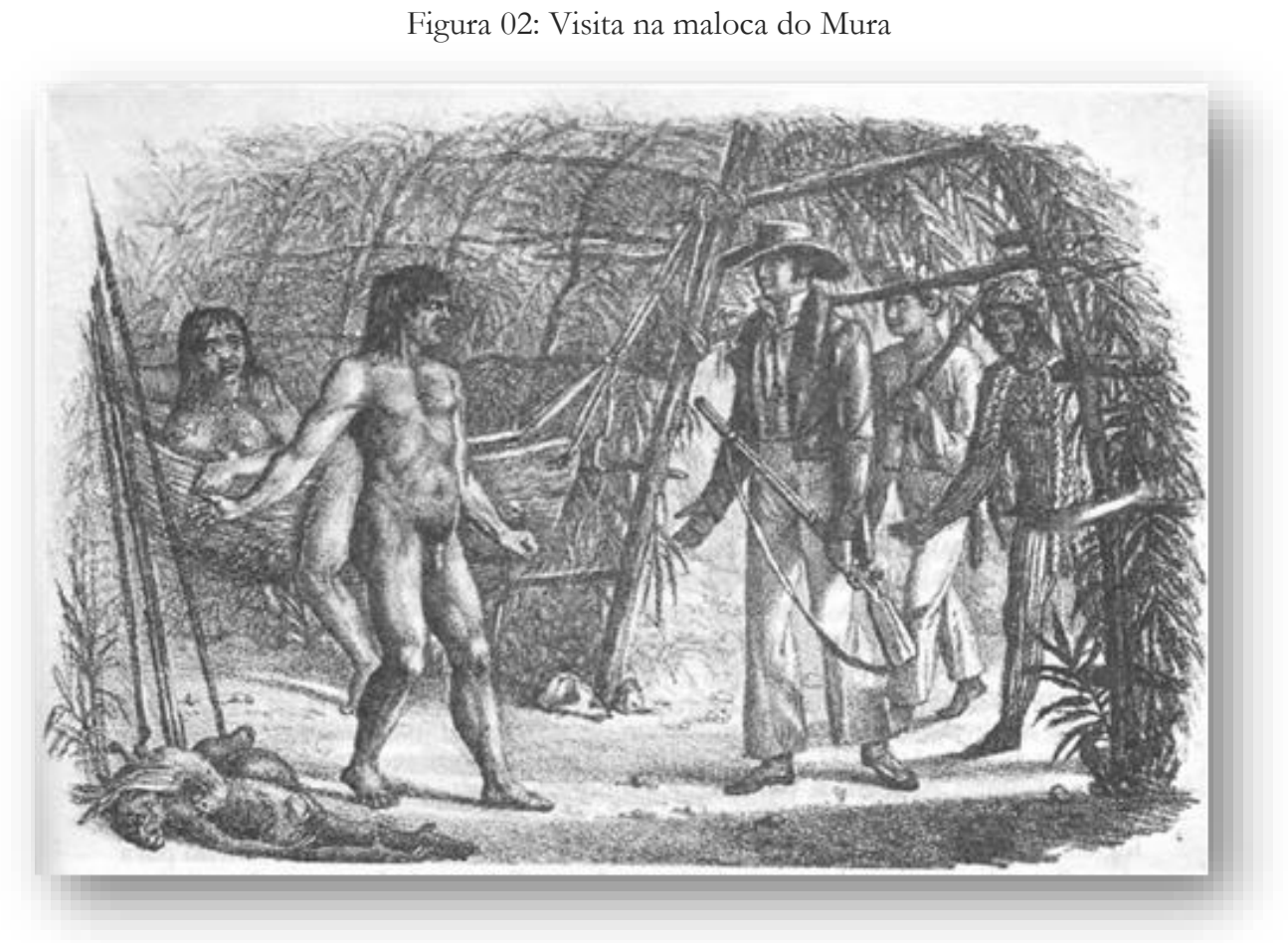

Fonte: o Livro A Viagem pelo Brasil - 1817-1820 de Spix e Martius, 1981. p. 153.

Para Joly (2013) as mensagens visuais das imagens sempre parecem ser realistas, mas existem muitas diferenças entre a imagem que é percebida de imediato e a realidade representada. A imagem em questão retrata a visão do desenhista do século XIX. Percebe-se pelos relatos que o objetivo da ilustração requisitada pelos viajantes não era exatamente apresentar os detalhes da cena descrita, mas registrar o que encontravam ao aportar em terra estrangeira. Temos a ênfase na descrição emocional do ato: indígenas assustados, com seus corpos nus, surpresos em sua intimidade diante da presença de um estranho vestido e com arma de fogo.

As imagens nos contam de um diálogo, narram uma história, uma época, congelam uma cena. Deixam transparecer expressões significativas de corpos: um indígena que recua e abre os braços, talvez para se defender ou para proteger sua casa e a mulher na rede. O homem armado dá um passo à frente, acompanhado de mais dois que parecem lhe escoltar e que sugerem expressões irônicas no rosto em oposição ao olhar arregalado e assustados dos indígenas. A imagem sugere o movimento de todos os retratados, o que indica ação e reação prontas a acontecer, sob a ótica do colonizador.

A figura 03 retrata a construção de uma nova embarcação pelos indígenas em atividade cotidiana. Mais uma vez os naturalistas registram os sujeitos em movimento, sugerindo atividades de caça, cuidado com os animais, preparo de alimentos e o lazer das crianças. A legenda da imagem nos indica que "o cacique está chegando de volta do ataque aos inimigos 
vizinhos, conduzindo os prisioneiros para vendê-los como escravos a Martius" (SPIX; MARTIUS, 1981, p. 231), tornado visível a forma como o viajante Martius fazia uso da mãode-obra indígena.

Figura 03: Indígenas constroem embarcação

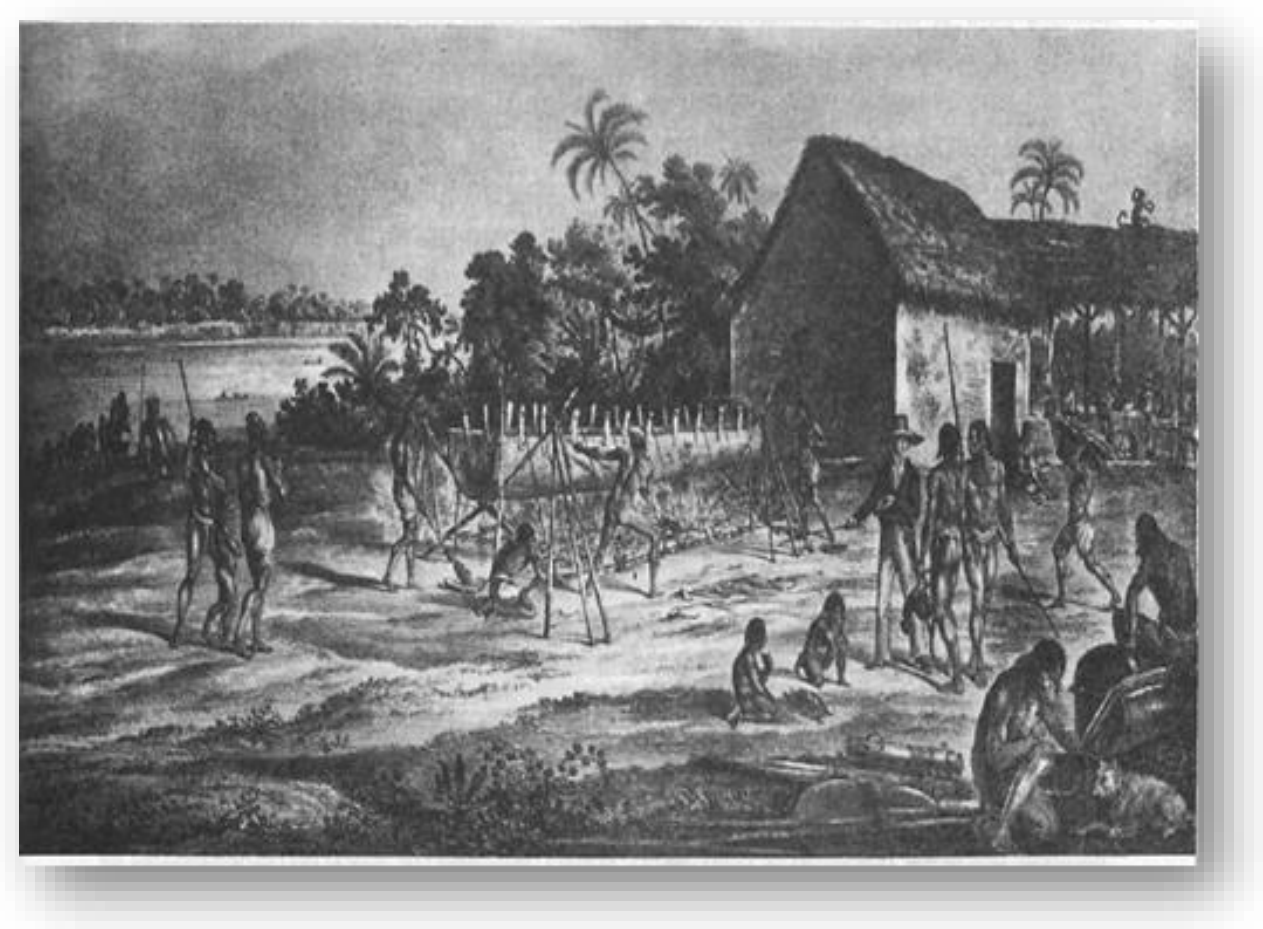

Fonte: o Livro A Viagem pelo Brasil - 1817-1820 de Spix e Martius, 1981. p. 231.

Este quadro (figura 04) traz a seguinte legenda: "visamos dar, com esta coleção de fieis retratos dos índios, uma ideia tanto da fisionomia comum de todas as raças vermelhas como do diferente nível de civilização, com o qual varia a expressão individual" (SPIX; MARTIUS, 1981, p. 243). Temos nesta proposta de retratar 'fielmente' os índios, o modo como os naturalistas estavam dispostos a fazer uma verdadeira taxonomia das populações. 
Figura 04: Coleção de retratos

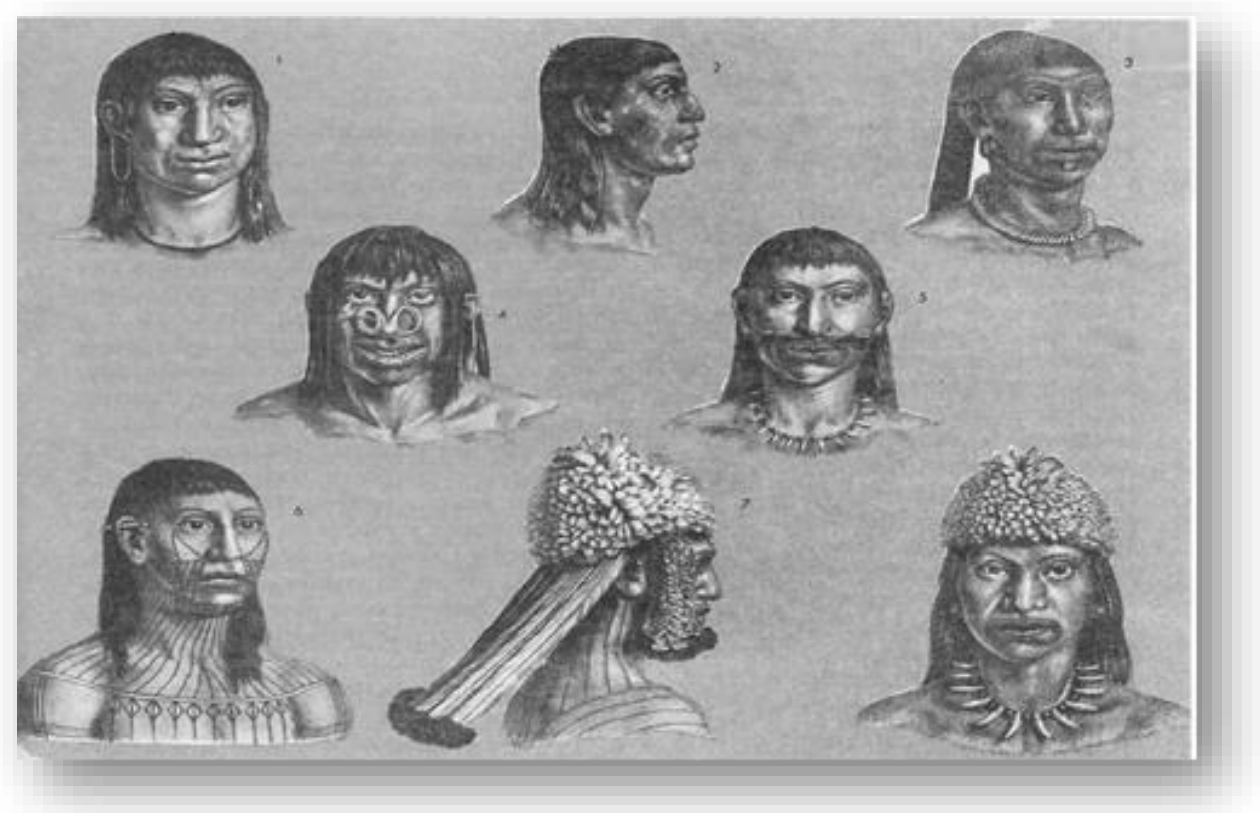

Fonte: o Livro A Viagem pelo Brasil - 1817-1820 de Spix e Martius, 1981. p. 243.

Observa-se uma comparação entre indígenas de diferentes etnias contactadas pelos viajantes, apresentados em uma singularidade ímpar, oriundos de núcleos distintos, com adornos diversos como cocares, ornamentos auriculares (alargadores) e principalmente a pigmentação corporal, rica em detalhes que expõem suas particularidades. As cabeças trazem expressões faciais diversas em posições distintas que registram diferentes formatos de crânio, o que nos evidencia a prevalência da comparação racial e biológica.

Esta outra imagem (figura 05) apresenta quatro indígenas da tribo dos Juris realizando uma dança guerreira. Percebem-se dois indígenas com lanças e escudos, em posições como se pretendessem atacar um ao outro, enquanto os outros dois estão assistindo ao ato. Um dos Juris que assiste parece estar exaltado de animação e encoraja a dança levantando um dos braços e batendo um dos pés no chão, enquanto o segundo está completamente imóvel, intrigado em observar atentamente o que ocorre. 
Figura 05: Dança guerreira dos Juris

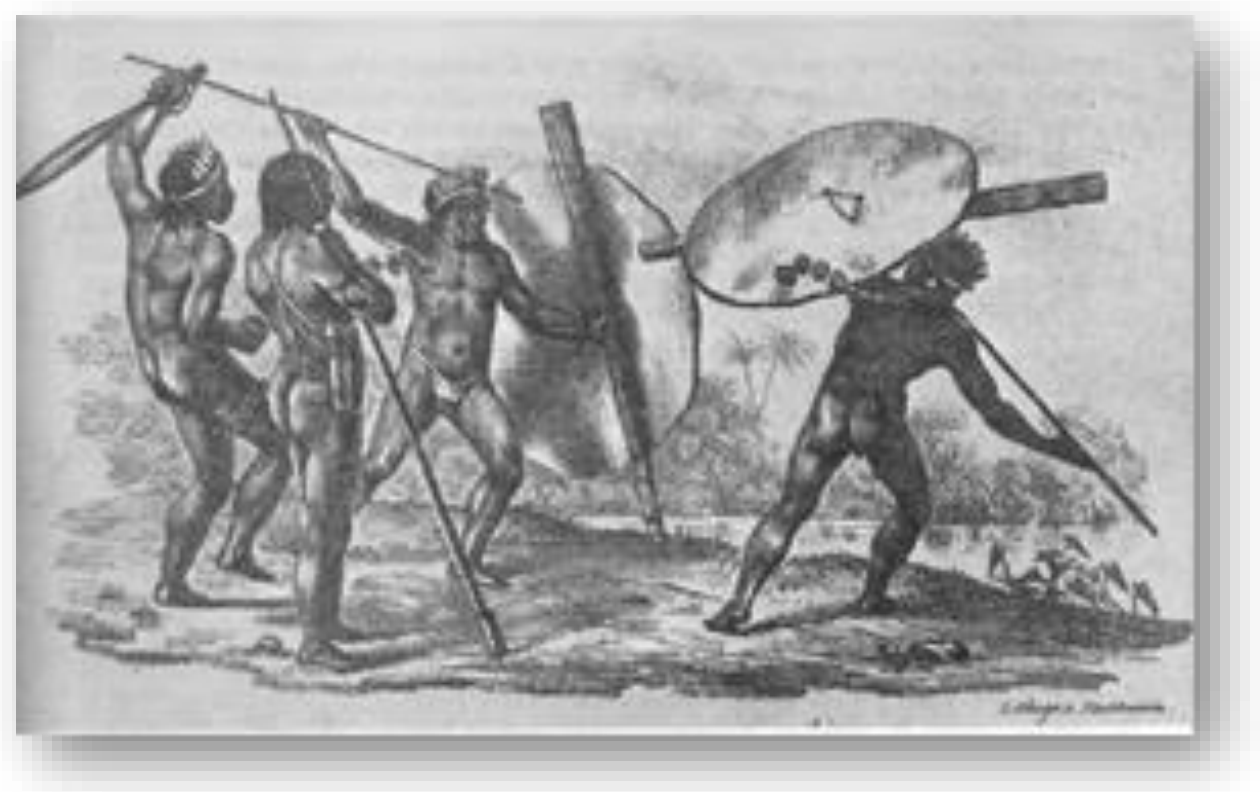

Fonte: o Livro A Viagem pelo Brasil - 1817-1820 de Spix e Martius, 1981. p. 195.

Os indígenas estão vestindo um tipo de tanga que cobre seus membros sexuais na parte da frente, deixando as nádegas expostas. Todos quatro possuem musculatura desenvolvida, sinal de grande atividade física. A imagem enfoca só estes quatro personagens, sem proporcionar detalhes sobre a localização em que eles estão presentes. Nota-se somente o chão de terra e um lago que está próximo a eles.

Esta imagem (figura 06) retrata um ritual dos Tecunas perante o nascimento de uma criança, que segue acompanhada de figuras mascaradas que representam o demônio e as feras do mato. "Depila-se o recém-nascido durante o préstito, enquanto ele é embalado lentamente pelas ruas do arraial, ao som de 'monótonas' cantigas e aos estalidos feitos na carapaça de tartaruga". (SPIX; MARTIUS, 1981.p. 181). 
Figura 06: Préstito festivo dos Tecunas.

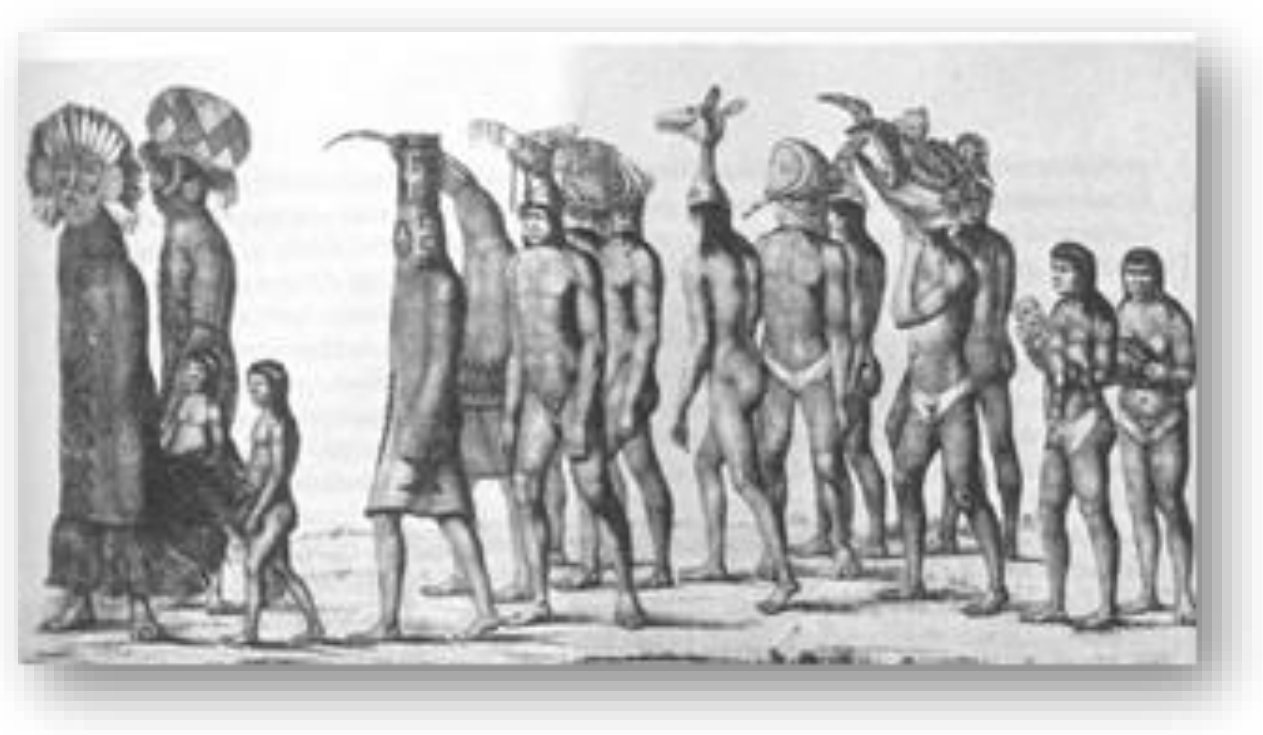

Fonte: o Livro A Viagem pelo Brasil - 1817-1820 de Spix e Martius, 1981. p. 181.

Percebe-se que se trata de uma ocasião especial, devido aos ornamentos e adereços que os indígenas trazem consigo: máscaras, vestimenta diferenciada e chapéus com formatos de animais. A comemoração é do nascimento dos recém-nascidos, que são carregados pelas índias, presentes no canto esquerdo da imagem. Com a legenda compreende-se a significação das máscaras, representando o demônio Jupari.

Os primeiros quatro indígenas na fila têm seus corpos cobertos por um tipo de túnica, juntamente com a máscara, não sendo possível identificá-los. Há duas crianças que seguem junto com os dois primeiros. Os outros indígenas têm seus corpos expostos, somente cobrindo seus órgãos sexuais, mostrando as nádegas descobertas. Em suas cabeças carregam chapéus em formato de animais locais. As duas mulheres que levam os recém-nascidos têm seus seios expostos, só cobrindo seus órgãos sexuais. A imagem proporciona a quem a vê a sensação de movimento de seus personagens. Eles seguem em fila andando como em um desfile. Os indígenas parecem olhar para diferentes cantos, como se houvesse pessoas os observando desfilar, mas não são mostradas na imagem. A última índia parece olhar para o artista, sabendo que este os observava.

Segundo os relatos dos viajantes, a tribo Maxuruna (figura 07) é feroz e guerreira, habitante do Rio Javari. A legenda da imagem indica: "testa e bochechas são tatuadas com traços; nas narinas, nas orelhas e no lábio inferior estão encaixadas rodelas; nos lábios estão espetados pequenos espinhos de palmeira; em cada canto da boca, uma comprida pena de arara"(SPIX; MARTIUS, 1981, p. 265). Muito marcante o grafismo nos desenhos faciais, juntamente com os adornos de penas e tipos de rodelas fixadas no rosto. 
Figura 07: Tribo Maxuruna.

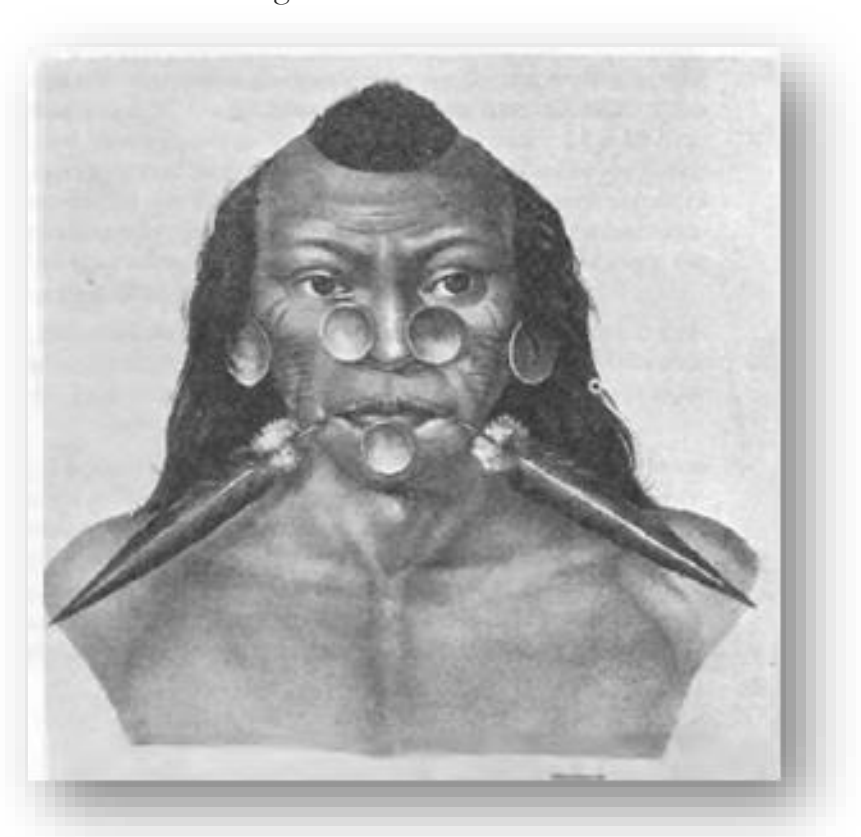

Fonte: o Livro A Viagem pelo Brasil - 1817-1820 de Spix e Martius, 1981. p. 265.

Segundo Joly (2013) não se pode excluir a imagem da linguagem verbal, de certa forma uma completa a outra, sempre caminham juntas, completam comentários, escritos, títulos, legendas, artigos, bulas etc. Ora põem-se dentro ou fora do contexto observado, na qual se chama de revezamento de narrativas nas histórias contadas através das imagéticas: "não só a linguagem verbal é onipresente como determina a impressão de 'verdade' ou mentira que uma mensagem visual desperta em nós" (JOLY, 2013. p. 116).

Joly nos faz atentar, aplicando suas reflexões ao nosso objeto de análise, para o modo como a narrativa dos viajantes busca comprovar o que encontraram por meio das imagens que produziram seus ilustradores. A imagem torna-se a produção da verdade, a comprovação do que viram e captaram. $\mathrm{E}$ as legendas e relatos que se alternam ao longo dos diários de viagem caminham junto com a mesangem visual como a explicá-las e, ao mesmo tempo, sustentá-las a partir das histórias contadas.

\section{CONSIDERAÇÕES FINAIS}

A leitura da obra "Viagem pelo Brasil - 1817-1820", de Spix e Martius, foi indispensável para obter dados importantes quanto à visão dos autores sobre as populações indígenas da Amazônia no século XIX. A partir dos dados coletados, descritos e analisados (tabelas verbais e imagéticas) foi possível a identificação das produções de sentido e expressões contidas nas imagens publicadas. Analisando-as no contexto de representações, nas técnicas utilizadas, abriu-se uma janela para observar o contexto sociocultural e histórico dos povos indígenas na Amazônia sob o olhar de Spix e Martius.

O ponto principal da pesquisa está na compreensão de como se deu a viagem ao desconhecido, realizada pelos viajantes, referindo-se aqui a hábitos, vivências e costumes do indígena, e a criação das imagéticas com base no registro de impressões e expressões. Observase que as interpretações criadas pelos brancos sobre os indígenas são os únicos registros que 
temos desse encontro.

Essa é uma história contada pelos europeus cientistas, na qual o indígena é inserido no texto ou na imagem como objeto do exótico e peça de coleções que vão compor o saber branco sobre as culturas indígenas americanas. Os estranhamentos com relação às culturas locais, que advém desses registros do passado, vão sedimentar uma memória sobre a Amazônia, resumida a indígenas nus, rituais míticos e pobreza. São vistos como selvagens, tidos como estranhos com seus saberes reduzidos e improdutivos, com relação aos saberes do colonizador.

\section{REFERÊNCIAS}

CARL Friedrich Philipp von Martius (disponível em: http://educacao.uol.com.br/biografias/vonmartius.jhtm).

FOUCAULT, Michel. A arqueologia do saber. 4.ed. Rio de Janeiro: Forense Universitária, 1995 (Coleção Campo teórico).

HOBSBAWM, Eric; RANGER, Terence. A invenção das tradições. Rio de Janeiro: Paz e Terra, 2008.

JOHANN Baptist von Spix (disponível em: http://www.bbm.usp.br/node/84).

JOLY, Martine. Introdução à análise da imagem. Papirus Editora, 14-Edição, 2013.

LAPLANTINE, François; TRINDADE, Liana. O que e imaginário? São Paulo: Brasiliense, 2012.

LARAIA, Roque de barros. Cultura: um conceito antropológico. 22.ed. Rio de Janeiro: Zahar, 2008. Disponível em: http://copyfight.me/Acervo/livros /Roque $\% \quad 20 \mathrm{de} \% \quad 20$ Barros $\% 20$ Laraia $\% 20 \% 20$ Cultura $\% 20$ um $\% 20$ conceito $\% 20$ antropolA $\%$ CC $\% 83 \%$ C2 $\%$ B3gico $\% 20 \% 5$ Bpdf $\% 5$ D.pdf.

MARTIUS, Carl Friedrich Philipp von; SPIX, Johann Baptist von. Viagem pelo Brasil - 1817-1820. Volume III. São Paulo. Ed. Da Universidade de São Paulo, 1981.

MEIRELES FILHO, João. Grandes expedições à Amazônia brasileira: 1500-1930. São Paulo: Metalivros, 2009.

MONTEIRO, José Rodolfo. O Atlas de Viagem de Spix e Martius. Anais do XXVI Simpósio Nacional de História - ANPUH. São Paulo, julho 2011 (disponível em: http://www.snh2011.anpuh.org/resources/anais/14/1295388187_ARQUIVO_JoseRodolfoMontei ro_UFMT.pdf).

SCHWARCZ, Lilia. O espetáculo das raças: cientistas, instituições e questão racial no Brasil 18701930. São Paulo: Companhia das Letras, 1993.

TODOROV, Tzvetan. A conquista da América: a questão do outro. 2. ed. São Paulo: Martins Fontes, 1988. 263p. 